\title{
Low awareness of adverse drug reaction reporting systems: a consumer survey
}

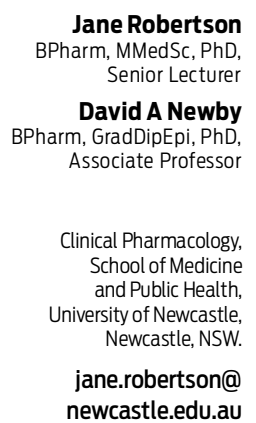

MJA 2013; 199: 684-686 doi: $10.5694 / \mathrm{mjal} 3.10069$ dverse drug reactions (ADRs) are a concern to patients, doc$t$ rs and the Australian health care system, with high rates of medication misadventure, ${ }^{1}$ adverse events in general practice patients, ${ }^{2}$ and hospitalisations. ${ }^{3}$ There are limited data on the long-term safety of newly marketed medicines and their use in patient groups not included in early clinical trials.

Most reporting of ADRs to the Therapeutic Goods Administration (TGA) is done by health professionals (doctors and pharmacists), hospitals and pharmaceutical companies, through mandatory reporting obligations. Consumers have been able to directly report possible ADRs to the TGA since 1964. Since 1990, there have been fewer than 7000 consumer ADR reports; 4190 of 74036 reports (5.7\%) between 2003 and 2009 were made by consumers, including a surge in 2009 $(1307 / 13298$ [9.8\%]) associated with the pandemic H1N1 influenza vaccination. ${ }^{4}$ Consumer reporting rates fell to $3 \%$ in $2011 .^{5}$ It is unclear if these rates are low because patients are unaware of ADRs or unaware of the processes by which reports can be made. Patients may prefer to report their suspicions of an ADR to state health departments (for vaccines) or a health professional, expecting that the doctor or pharmacist will report it to the relevant authority.

Recommendation 19 of a 2011 review of the transparency of the TGA requires the TGA to "more effectively facilitate the recognition and reporting of adverse events by health practitioners and consumers, and promote the adverse event reporting system" ${ }^{\prime}{ }^{6}$ With few data on the level of awareness of consumer reporting systems, we aimed to assess the knowledge and practices of a representative sample of the public regarding ADR reporting.

\section{Methods}

We collected data in two ways: a computer-assisted telephone interview

\section{Abstract}

Objective: To determine levels of public awareness of consumer adverse drug reaction (ADR) reporting systems in Australia.

Design, setting and participants: Cross-sectional study conducted in 2012 of residents of the Hunter Valley region of New South Wales, who participated in a computer-assisted telephone interview (CATI), and a national sample, who completed an online Pureprofile survey.

Main outcome measures: Proportion of respondents experiencing ADRs; the type of medicine involved; whether participants reported the adverse event and to whom; awareness and use of existing consumer ADR reporting mechanisms.

Results: There were 2484 CATI respondents and 2497 Pureprofile respondents. Side effects with medicines were very common ( $46.3 \%$ of respondents), most relating to prescription medicines $(88.4 \%)$. Among respondents who had experienced a side effect, $84.6 \%$ reported the event to a health care professional, most often a general practitioner. Awareness of consumer ADR reporting schemes was low (10.4\%). Of 217 respondents who had experienced a side effect and were aware of consumer reporting schemes, 46 (21.2\%) had reported an ADR using one of these schemes.

Conclusions: Consumers can contribute to our understanding of medicines safety, but there is low awareness of available reporting systems. Some consumers aware of ADR self-reporting systems appear prepared to use them, but promotion of and education on how to use reporting systems are required. Significant resources may be needed to support an enhanced consumer reporting scheme.

(CATI) conducted by the Hunter Valley Research Foundation (HVRF; http:// hvrf.com.au), and an online survey using a Pureprofile research panel (http://www.pureprofile.com/au).

The HVRF conducts regular CATI wellbeing surveys in the Hunter, Upper Hunter and Central Coast regions of New South Wales, and researchers can add questions to these multipurpose surveys. Landline telephone numbers are selected from the electronic White Pages. Random selection is used for both the telephone numbers and the household participant (substitutions are not permitted). Informed verbal consent is obtained from participants. The interviews were conducted during September and October 2012.

Pureprofile provides access to an online panel of 80000 Australian account holders (aged $\geqslant 18$ years) who provide detailed profile information on registration. The online survey was conducted in October 2012 using SurveyMonkey. Participants had to read an information sheet before accessing the survey questions, and completion of the survey was taken as consent to participate. Quota sampling was used to ensure equal partic- ipation of men and women across 10 year age bands and in proportion to population by state.

Following a similar study in the United Kingdom, ${ }^{7}$ respondents were asked if they had ever had side effects from a medicine, the type of medicine involved, whether they informed a health professional, reasons for not reporting the side effect, awareness of consumer reporting schemes (and which ones) and whether they had used this mechanism for reporting. Demographic data were also collected from respondents. The data are summarised here using descriptive statistics.

The study was approved by the University of Newcastle Human Research Ethics Committee (H-20120210).

\section{Results}

Of 3520 eligible household contacts, 2484 telephone interviews were completed (response rate, $70.6 \%$ ). There were 2497 completed surveys from the Pureprofile research panel. While the quota sampling used for the Pureprofile survey ensured similar proportions of respondents by sex, the CATI 
respondents were more likely to be female $(59.6 \%)$ (Box 1). CATI respondents were also generally older than Pureprofile respondents (52.5\% v $21.3 \%$ aged $\geqslant 60$ years) and often reported pensioner retired status (41.6\%). More Pureprofile than CATI respondents reported having a university-level education $(33.2 \% \mathrm{v}$ $18.1 \%$ ).

Responses from the two groups combined indicated that side effects of medicines were very common (46.3\% of respondents) (Box 2), with most relating to prescription medicines $(88.4 \%)$. Among respondents who had experienced a side effect, $84.6 \%$ reported the event to a health care professional, most often a general practitioner. The most common reasons for respondents not reporting it were that they had stopped using the medicine, the side effect was not serious enough, or they had expected it.

Among the whole study group, awareness of consumer reporting schemes was low (10.4\%). However, of 217 respondents who had experienced a side effect and were aware of consumer reporting schemes, 46 (21.2\%) had reported it using one of these schemes.

\section{Discussion}

This study found that many consumers experience medicine-related side effects, and most report these to a health professional. Few episodes result in a consumer ADR report, possibly relating in part to low awareness of reporting mechanisms. Compared with a similar UK study, more Australian consumers reported ever having side effects ( $46.3 \%$ v $23.5 \%$ ), while similar proportions reported the event to a health professional $(84.6 \% \mathrm{v}$ $85.5 \%){ }^{7}$ Awareness of the UK's Yellow Card Scheme for reporting was also low: 172 of 2028 respondents $(8.5 \%)$ were aware of the scheme, and only three had used it. ${ }^{7}$

The Adverse Medicine Events Line is a telephone reporting service that was introduced in Australia in 2003 to allow consumers to report suspected ADRs to the TGA and receive advice about side effects. Analysis of the use of this service demonstrated that consumers can identify potential

1 Characteristics of respondents, by survey group*

\begin{tabular}{|c|c|c|c|}
\hline & CATI $(n=2484)$ & Pureprofile ( $n=2497)$ & All $(n=4981)$ \\
\hline \multicolumn{4}{|l|}{ Sex } \\
\hline Men & $1003(40.4 \%)$ & $1208(48.4 \%)$ & 2211 (44.4\%) \\
\hline Women & 1481 (59.6\%) & $1216(48.7 \%)$ & $2697(54.1 \%)$ \\
\hline \multicolumn{4}{|l|}{ Age } \\
\hline 18-29 years & $119(4.8 \%)$ & $513(20.5 \%)$ & $632(12.7 \%)$ \\
\hline 30-39 years & $203(8.2 \%)$ & $484(19.4 \%)$ & $687(13.8 \%)$ \\
\hline 40-49 years & $332(13.4 \%)$ & $498(19.9 \%)$ & $830(16.7 \%)$ \\
\hline $50-59$ years & $527(21.2 \%)$ & $387(15.5 \%)$ & $914(18.3 \%)$ \\
\hline $60-69$ years & $623(25.1 \%)$ & $383(15.3 \%)$ & 1006 (20.2\%) \\
\hline$\geqslant 70$ years & $680(27.4 \%)$ & $150(6.0 \%)$ & 830 (16.7\%) \\
\hline \multicolumn{4}{|l|}{ Work status } \\
\hline Full-time & $637(25.6 \%)$ & $1006(40.3 \%)$ & 1643 (33.0\%) \\
\hline Part-time & 403 (16.2\%) & $461(18.5 \%)$ & $864(17.3 \%)$ \\
\hline Pensioner retired & 1034 (41.6\%) & $434(17.4 \%)$ & $1468(29.5 \%)$ \\
\hline Other & $254(10.2 \%)$ & $528(21.1 \%)$ & 782 (15.7\%) \\
\hline \multicolumn{4}{|l|}{ Highest qualification } \\
\hline No post-school & 1011 (40.7\%) & $822(32.9 \%)$ & 1833 (36.8\%) \\
\hline Certificate or diploma & 1022 (41.1\%) & $748(30.0 \%)$ & 1770 (35.5\%) \\
\hline University & $449(18.1 \%)$ & $830(33.2 \%)$ & 1279 (25.7\%) \\
\hline
\end{tabular}

medication risk, report novel adverse reactions to prescription and complementary medicines, and identify serious reactions and drug-induced hospitalisations not reported by health professionals. ${ }^{8}$ A UK study has found that, compared with reports made by health care professionals, patient ADR reports tend to be longer, contain more suspected ADRs, and refer to more than one suspected drug. ${ }^{9}$ Health care professionals were more likely to refer to hospitalisation and life-threatening events, whereas consumers reported events that affected everyday activities, referred to symptoms and stressed their severity, and highlighted the emotional and social impact on their lives. The World Health Organization is promoting the role of the consumer in spontaneous ADR reporting as an adjunct to existing pharmacovigilance strategies and has developed guidance for establishing effective consumer reporting systems. ${ }^{10}$

This interest in consumer ADR reporting comes at a time of relative decline in reporting by health care professionals. Of about 14400 reports received by the TGA in 2011, only $7 \%$ were submitted by GPs, ${ }^{5}$ compared with $28 \%$ of the 10981 reports received in 2003. ${ }^{11}$ Between 2003 and
2011, the proportion of ADR reports received from pharmaceutical companies increased from $28 \%$ to $52 \% .{ }^{4,5} \mathrm{~A}$ similar decline in GP ADR reporting has also occurred in the UK. ${ }^{12}$

There are likely multiple reasons for the decline in GP reporting. While medical specialty has been identified as a key influence on underreporting of ADRs by physicians, other influencing factors include ignorance about what should be reported; diffidence (fear of appearing ridiculous for reporting suspected ADRs); lethargy (procrastination and lack of interest or time to report); indifference (a belief that reporting would make little contribution to medical knowledge) and insecurity (lack of certainty of the drug causing the ADR). ${ }^{13}$ The Royal Australasian College of Physicians has recently suggested Australian doctors should receive payment for completing ADR reports. ${ }^{14}$

For consumers, it seems that lack of awareness of the reporting mechanisms is a major limiting factor. If the TGA is to facilitate and promote adverse event reporting by consumers, education is the first step. This could include posters in pharmacies, education in schools and community organisations, media promotion, and encouragement from health professionals. Reporting methods also need 
2 Participant responses on survey assessing public awareness of consumer adverse drug reaction reporting systems

Survey question

\begin{tabular}{|c|c|}
\hline Have you ever had side effects from any medicine? & $n=4910$ \\
\hline Yes & $46.3 \%(2275)$ \\
\hline No & $49.4 \%(2427)$ \\
\hline Don't know & $4.2 \%(208)$ \\
\hline $\begin{array}{l}\text { The last time you had a side effect, where did you obtain } \\
\text { the medicine? }\end{array}$ & $n=1917$ \\
\hline I got it at a pharmacy with a prescription & $88.4 \%(1695)$ \\
\hline I purchased it over-the-counter at the pharmacy & $5.8 \%(111)$ \\
\hline I purchased it at a supermarket or other shop & $0.5 \%(9)$ \\
\hline It is a herbal or complementary medicine & $0.5 \%(9)$ \\
\hline Don't know/can't remember/other & $4.9 \%(93)$ \\
\hline $\begin{array}{l}\text { Did you tell your GP or other health care professional } \\
\text { about the side effect? }\end{array}$ & $n=2268$ \\
\hline Yes & $84.6 \%(1918)$ \\
\hline No & $14.6 \%(330)$ \\
\hline Don't know & $0.9 \%(20)$ \\
\hline Who did you tell $?^{\dagger}$ & $n=1918$ \\
\hline General practitioner & $89.4 \%(1714)$ \\
\hline Specialist & $27.2 \%(522)$ \\
\hline Pharmacist & $20.4 \%(391)$ \\
\hline Practice nurse & $8.3 \%(160)$ \\
\hline State health department & $1.3 \%(25)$ \\
\hline Other & $5.8 \%(111)$ \\
\hline Why didn't you tell anyone about the side effect? ${ }^{\dagger}$ & $n=330$ \\
\hline The side effect was not serious enough & $46.4 \%(153)$ \\
\hline I stopped using the medicine & $31.8 \%(105)$ \\
\hline I was expecting the side effect & $24.8 \%(82)$ \\
\hline I didn't want to bother anyone. It was unnecessary & $16.4 \%(54)$ \\
\hline I didn't realise the side effect was due to the medicine & $7.3 \%(24)$ \\
\hline I am a GP or health care professional & $1.8 \%(6)$ \\
\hline Don't know & $1.5 \%(5)$ \\
\hline $\begin{array}{l}\text { Other (including being embarrassed, abroad, didn't } \\
\text { read instructions) }\end{array}$ & $20.9 \%(69)$ \\
\hline $\begin{array}{l}\text { Are you aware of any reporting schemes for consumers } \\
\text { for adverse drug effects and adverse reactions? }\end{array}$ & $n=4981$ \\
\hline Yes & $10.4 \%(520)$ \\
\hline No & $87.5 \%(4360)$ \\
\hline Don't know & $2.0 \%(101)$ \\
\hline What schemes are you aware of $?^{\dagger}$ & $n=520$ \\
\hline $\begin{array}{l}\text { Reporting to the government (Therapeutic Goods } \\
\text { Administration) }\end{array}$ & $27.9 \%(145)$ \\
\hline Reporting to a state health department & $24.6 \%(128)$ \\
\hline Reporting to a telephone hotline at a hospital & $21.3 \%(111)$ \\
\hline $\begin{array}{l}\text { Reporting to a telephone hotline at the National } \\
\text { Prescribing Service }\end{array}$ & $16.3 \%(85)$ \\
\hline Other & $4.2 \%(22)$ \\
\hline $\begin{array}{l}\text { The last time you had a side effect, did you report it } \\
\text { yourself using a consumer reporting scheme? }\end{array}$ & $n=217$ \\
\hline Yes & $21.2 \%(46)$ \\
\hline No & $75.6 \%(164)$ \\
\hline Don't know & $3.2 \%(7)$ \\
\hline How did you report it to the authorities? ${ }^{\dagger}$ & $n=46$ \\
\hline Telephoned them & $63.0 \%(29)$ \\
\hline Email or online & $47.8 \%(22)$ \\
\hline Wrote a letter & $26.1 \%(12)$ \\
\hline Spoke to someone in person & 0 \\
\hline
\end{tabular}

* Denominators vary due to missing responses and conditional questions. Cells do not always total $100 \%$ due to rounding. † Multiple answers allowed. to be easy to access and use. Possibilities include a smartphone application that is part of a medication management system.

However, greater participation in ADR reporting by consumers presents challenges. The TGA would need to be adequately resourced to respond to a larger number of consumer reports, to interpret the information provided, and to provide feedback or acknowledgement to the reporter. There is limited evidence from other jurisdictions to establish the value of such systems. A system allowing focused follow-up of patients with newly prescribed medicines has been used in Canada to enhance detection of ADRs. ${ }^{15}$ At both 3 days and 2 weeks after starting a new medicine, the system generated a phone call to the patient. Using interactive voice response technology, patients were asked four questions about possible medicine problems and offered the opportunity to speak to a pharmacist. This approach differs from other prescription event monitoring systems ${ }^{16}$ by proactively engaging consumers in their medicine management.

The use of two different data sources for our study overcame the potential representativeness problems of older, more often female respondents in CATI surveys, and younger respondents in online surveys. Key advantages of the online survey were the lower cost, high response rate and rapid completion of the survey. Despite some demographic differences between the two groups, awareness and use of consumer ADR reporting mechanisms were low in each (data not shown).

Consumers can contribute to our understanding of medicines safety, and we found that some consumers who are aware of self-reporting systems appear prepared to use them. First, consumers need to know that they can report, and then how to do so.

Competing interests: No relevant disclosures.

Received 20 Jan 2013, accepted 15 Aug 2013.
1 Pit SW, Byles JE, Cockburn J. Prevalence of self-reported risk factors for medication misadventure among older people in general practice. J Eval Clin Pract 2008; 14: 203-208.

2 Miller GC, Britt HC, Valenti L. Adverse drug events in general practice patients in Australia. Med J Aust 2006; 184: 321-324.

3 Burgess CL, Holman CD, Satti AG. Adverse drug reactions in older Australians, 1981-2002. Med J Aust 2005; 182: 267-270.

4 van Hunsel F, Härmark L, van Grootheest K. Review of direct patient reporting of adverse drug reactions: an 11 country survey on behalf of the Monitoring Medicines project. Dec 2010. http://www.monitoringmedicines.org/ graphics/26652.pdf (accessed Dec 2012).

5 Therapeutic Goods Administration. Adverse event reporting in Australia in 2011. Canberra: TGA, 2012. http://www.tga.gov.au/pdf/ medicines-statistics-2011.pdf (accessed Jan 2013).

6 Panel to Review the Transparency of the Therapeutic Goods Administration. Review to improve the transparency of the Therapeutic Goods Administration: final report June 2011. Canberra: Department of Health and Ageing, 2011. http://www.tga.gov.au/pdf/consult/ review-tga-transparency-110l-final-report.pdf (accessed May 2012).

7 Fortnum H, Lee AJ, Rupnik B, Avery A; Yellow Card Study Collaboration. Survey to assess public awareness of patient reporting of adverse drug reactions in Great Britain. J Clin Pharm Ther 2012; 37: 161-165.

8 McGuire T, Moses G. What do consumers contribute to pharmacovigilance? Lessons from the AME line. In: Proceedings of the National Medicines Symposium 2006; 2006 Jun 7-9; Canberra. http://www.icms.com.au/ nms2006/abstract/132.htm (accessed May 2012).

9 Avery AJ, Anderson C, Bond CM, et al. Evaluation of patient reporting of adverse drug reactions to the UK 'Yellow Card Scheme': literature review, descriptive and qualitative analyses, and questionnaire surveys. Health Technol Assess 2011; 15: 1-234, iii-iv.

10 World Health Organization. Safety monitoring of medical products: reporting system for the general public. Geneva:WHO, 2012. http:// www. who.int/medicines/areas/quality safety/safety_efficacy/EMP_Consumer Reporting_web_v2.pdf (accessed Jun 2013).

11 Berbatis C. Primary care and pharmacy: 3. National adverse reaction reporting and pharmacists in Australia. i2P - Information To Pharmacists 2008; (71). http://archive.i2p. com. au/?page=print/article\&id=971 (accessed Jun 2013).

12 Wise J.GPs are urged to report adverse drug reactions after a $37 \%$ slump over nine years. BMJ 2013; 346: f690.

13 Lopez-Gonzalez E, Herdeiro MT, Figueiras A. Determinants of under-reporting of adverse drug reactions: a systematic review. Drug Saf 2009; 32: 19-31.

14 Hartley J. Pay doctors to report adverse events. Australian Doctor 2013; 1 Mar. http:// www.australiandoctor.com.au/news/latestnews/pay-doctors-to-report-adverse-drugevents-racp (accessed Jun 2013).

15 Forster AJ, Auger C; ISTOP ADE Investigators. Using information technology to improve the monitoring of outpatient prescribing. JAMA Intern Med 2013; 173: 382-384.

16 Heeley E, Riley J, Layton D, et al. Prescriptionevent monitoring and reporting of adverse drug reactions. Lancet 2001; 358: 1872-1873. 